Angelika Siehr

\title{
Das Recht am öffentlichen Raum
}

Theorie des öffentlichen Raumes und die räumliche Dimension von Freiheit

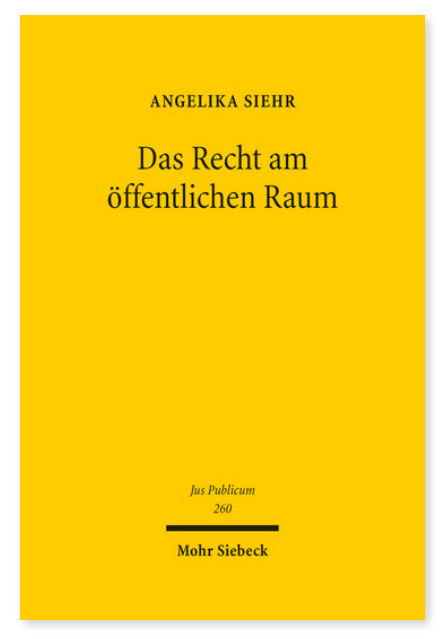

2016. XXXIV, 770 Seiten. JusPubl 260

ISBN 978-3-16-152554-4

DOI 10.1628/978-3-16-152554-4

eBook PDF 154,00€

ISBN 978-3-16-152450-9

Leinen $154,00 €$
Der urbane öffentliche Raum wird heute zunehmend durch Shoppingmalls und privatisierte Verkehrsflächen (Bahnhöfe, Flughäfen, auch ganze Stadtquartiere) geprägt. Diese Privatisierungstendenzen stellen eine neue rechtstheoretische und (grund)rechtsdogmatische Herausforderung dar: Wie kann der öffentliche Raum, dessen Existenz Voraussetzung für die Ausübung von (Kommunikations)Grundrechten ist, rechtlich rekonstruiert werden? Welche Bedeutung kommt insoweit dem Eigentum in öffentlicher Hand in einer demokratischen Ordnung zu? Vor dem Hintergrund eines republikanischen Demokratieverständnisses leitet Angelika Siehr aus dem Eigentum in öffentlicher Hand ein Recht am öffentlichen Raum ab, das die räumliche Dimension der allgemeinen Handlungsfreiheit schützen soll. Umgekehrt nimmt sie auch zu der Frage Stellung, welchen Bindungen das Eigentum Privater in semi-öffentlichen Räumen unterliegt.

Angelika Siehr Studium der Rechts- und Politikwissenschaft in Marburg, Lausanne und Kiel; Master of Laws der Yale Law School; Promotion und 2011 Habilitation an der Humboldt-Universität zu Berlin; Rechtsanwältin in Kiel; Lehrstuhlvertretungen in Freiburg, Bielefeld und Konstanz; seit WS 2011/12 Professorin für Öffentliches Recht, Völkerrecht, Rechtsphilosophie und Bildungsrecht an der Universität Bielefeld.
Jetzt bestellen:

https://mohrsiebeck.com/buch/das-recht-am-oeffentlichen-raum-9783161525544?no_cache=1

order@mohrsiebeck.com

Telefon: +49 (0)7071-923-17

Telefax: $+49(0) 7071-51104$ 